\title{
Microstructure and Corrosion Resistance of Fe314 Alloy Prepared by Laser Cladding on EA4T Steel Surface
}

\author{
Yujiang Xie ${ }^{1,2}$, Bensheng Huang ${ }^{1, *}$, Jia Zhuang ${ }^{1, *}$, Wenjing Chen ${ }^{3}$, Jie Hu ${ }^{1}$ \\ ${ }^{1}$ School of New Energy and Materials, Southwest Petroleum University, Chengdu, 610500, China \\ ${ }^{2}$ School of Engineering, Southwest Petroleum University, Nanchong, 637001, China \\ ${ }^{3}$ School of Materials Science and Engineering, Xihua University, Chengdu, 610039, China \\ "E-mail: hbslxp@163.com; zhuangjia1001@126.com
}

doi: $10.20964 / 2020.11 .26$

Received: 26 July 2020 / Accepted: 27 August 2020 / Published: 30 September 2020

\begin{abstract}
An Fe314 alloy cladding layer was prepared on EA4T steel by laser cladding. Scanning electron microscopy (SEM), X-ray diffraction (XRD), energy dispersive spectroscopy (EDS) and an electrochemical workstation were used to investigate the microstructure, phase composition, element distribution and corrosion resistance of the cladding layer. The results showed that the microstructure of the cladding layer is columnar crystal and equiaxial crystal, the interior of the cladding layer grains is mainly an austenite phase, and the intergranular precipitates mainly include $\mathrm{Fe}_{3} \mathrm{C}, \mathrm{FeB}$ and $\mathrm{Cr}_{3} \mathrm{C}_{2}$. The closer the cladding zone is to the bonding zone, the lower the $\mathrm{Cr}$ element content and the higher the $\mathrm{Fe}$ element content. Compared with the substrate, the cladding layer has excellent corrosion resistance.
\end{abstract}

Keywords: EA4T steel; laser cladding; microstructure; corrosion resistance

\section{$\underline{\text { FULL TEXT }}$}

(C) 2020 The Authors. Published by ESG (www.electrochemsci.org). This article is an open access article distributed under the terms and conditions of the Creative Commons Attribution license (http://creativecommons.org/licenses/by/4.0/). 